Int. J. Electrochem. Sci., 15 (2020) $1622-1633$

\title{
Phosphorus-Carbon Composite for a Negative Electrode of a Sodium-ion Battery
}

\author{
Alexander Skundin ${ }^{1, *}$, Dmitry Gryzlov ${ }^{1}$, Tatiana Kulova ${ }^{1}$, Yulia Kudryashova ${ }^{1,2}$, Anna Kuz'mina ${ }^{1}$ \\ ${ }^{1}$ Frumkin Institute of Physical Chemistry and Electrochemistry of the RAS, 31-4 Leninskii ave., \\ 119071 Moscow, Russia \\ ${ }^{2}$ National Research University "Moscow Power Engineering Institute", 14 Krasnokazarmennaya str., \\ 111250 Moscow, Russia. \\ *E-mail: askundin@mail.ru
}

doi: $10.20964 / 2020.02 .47$

Received: 9 October 2019 / Accepted: 19 November 2019 / Published: 31 December 2019

Phosphorus-carbon composite was prepared by combined method consisting of grinding a mixture of red phosphorus with Ketjenblack EC300J followed by sublimation-condensation with simplified temperature scenario. The composite was characterized by XRD, EDX, SEM, and Raman-spectroscopy. The electrodes with such a composite were studied by galvanostatic cycling and cyclic voltammetry. The electrodes delivered the discharge capacity of $1870 \mathrm{mAh} \mathrm{g}^{-1}$ at $\mathrm{C} / 20$ and $190 \mathrm{mAh} \mathrm{g}^{-1}$ at $10 \mathrm{C}$. The sodium effective diffusion coefficient in the composite was estimated as $(3-4)^{*} 10^{-14} \mathrm{~cm}^{2} \mathrm{~s}^{-1}$.

Keywords: sodium-ion batteries, phosphorus-carbon composites, sublimation-condensation method, sodium insertion, sodium diffusion coefficient

\section{$\underline{\text { FULL TEXT }}$}

(C) 2020 The Authors. Published by ESG (www.electrochemsci.org). This article is an open access article distributed under the terms and conditions of the Creative Commons Attribution license (http://creativecommons.org/licenses/by/4.0/). 